\title{
So who wants to be a consultant general psychiatrist
}

\author{
John Milton
}

This study addresses the perception among senior trainees that the lot of a consultant general psychiatrist is currently not a happy one and that transition from training to consultant grade can be difficult. Reasons for this are explored and altematives suggested that might make the move from senior/ specialist registrar to consultant general psychiatrist a more rewarding and attractive proposition.

Most psychiatrists will be aware that the number of consultant vacancies in general psychiatry has recently increased (Table 1). While some vacancies arise from premature retirements (Kendell \& Pearce, 1997) or consultant grade expansion, it remains likely that some of the problem lies in recruitment to unattractive posts and the difficulties in transition to consultancy feared by many senior trainees.

\section{Senior/specialist registrar grade: the time of your life?}

The general principle behind the Calman Report on Specialist Medical Training (Department of Health, 1993) was to improve the quality of higher specialist training by introducing a unified training grade and shortening required training to increase throughput of trainees to consultant level. However, many senior registrars and newly appointed specialist registrars (SpRs) appear to be extending their training, opting for dual accreditation in sub-specialities in addition to general psychiatry. While adding to knowledge, this arguably prolongs senior training, delaying consultant appointments.

Table 1. Consultant general psychiatrist vacancies in England, Wales and Scotland, 1994-1996

\begin{tabular}{lllll}
\hline Year & Total posts & $\begin{array}{l}\text { Total } \\
\text { vacancies (\%) }\end{array}$ & $\begin{array}{l}\text { Filled by } \\
\text { locums }\end{array}$ & $\begin{array}{l}\text { Vacant } \\
\text { posts (\%) }\end{array}$ \\
\hline 1994 & 1409 & $157(11.1)$ & 100 & $47(3.3)$ \\
1995 & 1466 & $178(12.1)$ & 117 & $61(4.2)$ \\
1996 & 1524 & $210(13.8)$ & 147 & $63(4.1)$ \\
\hline
\end{tabular}

Adapted from Royal College of Psychiatrists. Annual Census of Psychiatric Staffing 1994-1996.
It has long been acknowledged that senior registrar training is a privileged time. First, it is described in hindsight by many consultants as their last opportunity to conduct research, publish and pursue special interests within psychiatry. Dedicated sessional time for research allows senior registrars to come to their clinical work free from distraction caused by squeezing in research between busy clinical duties. Second, it allows the blossoming of autonomous clinical decision-making without the ultimate "buck stop'. Third, senior registrars are encouraged to attend career developing courses, conferences and obtain management experience.

\section{Transition to consultant}

The purpose of training grades is that ultimately enough experience and knowledge is accrued to allow functioning as a consultant, and several core objectives for higher training have been determined (Plummer, 1994). From a survey of recently appointed consultants (Haddad \& Creed, 1996) and talking to many new consultants, training for consultancy is felt to be a far from seamless process. Several possible reasons might be proposed.

Senior registrars are generally shielded from exposure to many administrative pressures from staffing problems to patient complaints that arise within most directorate and team structures. Two surveys of newly appointed consultants revealed deficiencies in training related to managerial processes (Loane \& Barker, 1996). personal management and information technology (Haddad \& Creed, 1996). Second, despite short consultant locum experience when covering senior holiday or sick leave, the traditional apprenticeship element to the final stages of medical training appears to have been lost. Third, and perhaps hardest of all, is the change in how a new consultant is perceived by trainee colleagues who perhaps no longer see a new consultant as 'one of us' but as a more senior figure, engendering a sense of isolation in the early days. 


\section{Problems for consultants}

Concern regarding the changes occurring for consultants has been expressed generally within medicine. A survey of consultant physicians' attitudes to the proposed Calman changes leading to consultant-provided services suggested that over $70 \%$ would not resume emergency residential duties and would withdraw from general medical duties (Mather et al, 1995).

Consultant general psychiatrists too are under pressure. Overall changes in working practices including the move from institutional to community care and working towards a consultantprovided service to name but two, without adequate resources, have added to workloads. While stress and even mental disorders such as anxiety and depression have been increasingly reported across all medical disciplines (Caplan, 1994), emotional exhaustion and 'burn-out' within front-line community mental health staff in particular have recently been described (Rosser et al, 1996; Onyett et al, 1997).

Government and public perceptions have changed regarding responsibility and accountability of mental health professionals for the behaviour of their patients. Suicide or homicide inquiries have often appeared to fulfil a scapegoating' process and questions have been asked as to the value of the current system (Muijen, 1997). Further pressures arise from requirements to achieve service targets relating to league tables, for example waiting lists or patients seen. These often seem unrealistic or unachievable without significant alterations to clinical practices or statistics.

An increase in administrative procedures, including the Care Programme Approach, supervision registers and supervised discharge, have all encroached upon time available for other service matters. This also leaves less time for staff support and relevant managerial or directorate requirements for which a clinical psychiatrist's viewpoint would be influential.

There have been escalating pressures upon services which traditionally provide a 'front-line' response to psychological or behavioural problems, usually the general psychiatrist and community mental health team. An insidious change is the increasing expectation among the public and some other allied professional services for the 'medicalisation' of abnormal behaviour which is perceived as requiring mental health 'treatment'. One example might be referrals for anger management which, in a climate of unlimited resources could be an appropriate treatment provision, but is not one that can be routinely offered by most services.

For senior registrars evaluating their future career prospects or prospective employers, all of the above can either make the practice of general psychiatry in the new millennium seem a challenge or an incentive to seek an alternative psychiatric career path. Dual accreditation and practising within a speciality, academic or tertiary referral, service might offer advantages over general psychiatry. In such areas, although problems can be extremely complex, the type of response can be different to the 'firefighting' of general psychiatry, often allowing a more deliberate response.

\section{Possible solutions}

So what might smooth the transition towards and subsequent survival in a consultant general psychiatry post? The following are personal suggestions and are in addition to the usual practical issues of population size of sector. secretarial support, details of clinical team, salary and ability to work with incumbent colleagues.

\section{Final year senior registrar apprenticeship}

Although not reflecting the current view of the Joint Committee on Higher Psychiatric Training regarding the supernumerary status of senior registrars, a tailoring of final post senior registrar attachments to increasingly mirror aspects of consultant role (e.g. by delegation of certain tasks or a part of a sector under supervision), therefore commencing a new consultant job, although clearly a change in status, may prove a more seamless process.

\section{Managerial experience}

Most regions now have courses for explaining personal and organisational management principles. These can be augmented by attending senior medical, directorate or trust board meetings, or by observing the work of senior managers.

\section{Job expectations and 'good will'}

Doctors generally work hard, take little sick leave and have a vocational element to their practice. These aspects can sometimes be stretched leading to an erosion of good will. An important element to any new job is setting out from the outset what is possible and achievable by an individual and by employers within limitations of time and resources.

\section{Mentoring}

Doctors can be poor acceptors of advice. In the early stages of a consultant post, a sympathetic, confidential, advisory ear (not necessarlly a sector team partner) would provide the kind of support most juniors have become accustomed 
to throughout training. Such a change in consultant culture has been proposed through a network of 'medical buddies' (Noble, 1997).

\section{Peer group support}

Associated with mental hospital closure was the dispersal of medical staff to isolated sector bases, away from previous centralised peer support (often a coffee room). Encouraging regular 'coffee room psychiatry' needs strict personal time management but is essential for informal information gathering and letting off steam.

\section{Information support}

The increasing rapidity with which decisionmaking is required calls for an information technology infrastructure to enable this. Evidence of an employer's commitment to accessible clinical information systems for the Care Programme Approach and supervision registers seems mandatory for any prospective consultant.

\section{Sabbaticals}

Not just 'carrots and sticks' but a commitment to, for example, short career breaks after five years service to encourage refreshment, retraining, travelling or publication. An alternative seen in some recently appointed posts is of honorary sessional academic status.

The job of consultant general psychiatrist should be challenging and rewarding. It would be unfortunate if successful recruitment to and maintenance in such posts was hindered by a sense of inadequate preparation at senior/ specialist registrar grade, negative preconceptions or potentially stressful job factors not considered prior to applying. Giving thought to job expectations for general psychiatric posts while a senior/specialist registrar, which should after all be the basis of senior training, will provide added effectiveness in the early stages after appointment. Failure to make changes will mean that general psychiatry runs the risk of burning itself out as well as its staff.

\section{References}

CAPLAN, R. (1994) Stress, anxiety and depression in hospital consultants, general practitioners and senior health service managers. British Medical Joumal, 309, 12611263.

DEPARTMENT OF HEALTH (1993) Hospital Doctors Training for the Future. The Report of the Working Group on Specialist Medical Training (Calman Report). MISC (93)31. London: HMSO.

HADDAD, P. \& CREED, F. (1996) Skdlls training for senior registrars. Psychiatric Bulletin, 20, 391-394.

KENDELL, R. E. \& PEARCE, A. (1997) Consultant psychiatrists who retired prematurely in 1995 and 1996. Psychiatric Bulletin, 21, 741-745.

LOANE, R. \& BARKER, A. (1996) Newly appointed consultants in old-age psychiatry and adequacy of higher training. Psychiatric Bulletin, 20, 388-390.

MATHER, H. \& ELKELES. R. ON BEHALF OF THE NORTH WEST Thames Diabetes and Endocrinology SPeciaust Group (1995) Attitudes of consultant physicians to the Calman proposals: a questionnaire survey. British Medical Journal, 311, 1060-1062.

MUwEN, M. (1997) Inquiries: who needs them? Psychiatric Bulletin, 21, 132-133.

NoBLE, B. (1997) Network of 'medical buddies' is needed (letter). British Medical Joumal, 314, 1908.

ONYETT, S. PILLGER, T. \& MULEN, M. (1997) Job satisfaction and burnout among members of community mental health teams. Journal of Mental Health, 6, 55-66.

PLUMmer, D. (1994) Objectives for Higher Psychiatric Training. London: Royal College of Psychiatrists.

ROSSER, D., JOHNSON, S., KUIPERS, E., et al (1996) Mental Health 'burnout' and job satisfaction among hospital and community-based mental health staff. British Joumal of Psychiatry, 169, 334-337.

John Milton, Research Fellow in Psychiatry, Department of Psychiatry. Duncan MacMillan House, Porchester Road, Nottingham NG3 6AA 